\title{
nature
}

\section{Fetuses and Parkinsonism}

\section{Concern about the use of fetal nervous tissue in the tentative treatment of Parkinsonism could easily be set to rest were not the underlying worry the use of abortion to remedy quite a different problem.}

There are at least two views of the attempts made in Sweden, Mexico and (now) Britain to treat Parkinsonism by means of tissue grafts, either of adrenal tissue or nervous tissue. One is that the procedure may in due course be a means by which large numbers of people and their relatives are relieved of the symptoms of common and distressing conditions; Parkinsonism is not the only debilitating disease that might in due course be tractable. The other view is that the use of fetal nervous tissue provokes ethical doubts so serious that this route to therapy must be barred (as it has already been impeded in the United States - see page 668). What is the truth?

The procedures so far carried out to rid people of parkinsonism by transplanting tissue are not cures, but essays in that direction. The immediate cause of Parkinsonism is a lack of the neurotransmitter dopamine in the cells of the part of the brain known (on account of its colour) as the substantia nigra, but nobody knows whether this is the ultimate cause; most probably there are several. The fact that L-dopa, the precursor of dopamine, temporarily alleviates the symptoms is a sign both that Parkinsonism may be treated as if it were a deficiency disease and that there is more than that to be understood.

Attempts at therapy by tissue-graft are based on experiments with laboratory animals, and have shown relief of the symptoms of the animal analogue of Parkinsonism both by grafts of adrenal tissue (potentially a source of catelcholamines, of which dopamine is one) and of fetal nervous tissue, distinguished from adult fetal tissue by the capacity of its cells to divide, possibly to differentiate according to the location in which they find themselves and perhaps more radically than L-dopa to remedy the underlying defect. But that is surmise only. Only time will tell what benefits will accrue to the patients. Only when there are large numbers of them will it be possible to judge whether either treatment has general value.

So why should there be a fuss in Britain that a surgical team in Birmingham has carried out two transplants of fetal nervous tissue? And why should Mr Robert Windom, assistant secretary for health in the US government, have instructed the National Institutes of Health not to continue in the field, using material from induced (as distinct from spontaneous) abortions, until an advisory committee on the subject has reported? There are (and certainly may be imagined) ethical problems in the use of fetal tissues for this or any other purpose. But there is also a close connection between these issues and the more contentious and political issue of induced abortion. Even in laconic Britain, there will be sparks flying when Mr David Alton's bill to reduce the time-limit for induced abortions comes up for debate in the House of Commons in a few weeks.

The ethical issues are easily listed. It would be wrong for a physician to procure an abortion to suit his patient's needs, but the remedy, which arises elsewhere in transplant surgery, is to erect a chinese wall between the physicians responsible for the patient and the donor, together with supervisory committees and even legal penalties for transgression. It would similarly be wrong for patients to conspire with their relatives to procure unwanted pregnancies, but the same chinese walls should suffice. Fears that, because transplant tissue must be as fresh as possible, there will be a temptation to use "live" fetuses as sources are less substantial; fetuses should not be aborted so late that they are likely to be capable of independent life (which is the case for a modest reduction of the British 28-week time-limit on abortion). Why should the physicians acting for people with Parkinson's disease be supposed to differ from their professional colleagues in being monsters?

Windom's distinction between induced and spontaneous abortions is even more illogical. Under specified conditions, induced abortions are legal in most of the United States, as they are in many other countries. So what can be the moral difference between fetal tissue resulting from an induced and from a spontaneous abortion? Is the real question implicit in Windom's instruction, as in the British fuss, one of abortion? Having, twenty years ago, chosen abortion as the remedy for unhappy social problems, societies seem now to wish they could dispense with the remedy as well, especially now that many of the problems have gone away. It would be a pity if that subliminal connection were to dish a potentially valuable therapy.

\section{Greens against genes}

\section{...West Germany starts further back. Molecular biologists should stir themselves.}

THERE may just be time to prevent the debate over genetic engineering in West Germany from turning into fisticuffs. Though the Bundestag first tackled the issue in 1984, the recommendations of the Enquete Kommission last year have set Bonn's ministries and committees the task of turning them into law (see page 672). With much of this going on in public, there is a danger that the debate will be a test of whose emotions are the more florid.

In the long run, everybody's interest is that the debate now joined about the proposed gene law should be conducted in a way that will not leave behind two exhausted armies of polemicists - one of them convinced it has been cheated of a deserved victory. But on present form there is just one army - that of those who say that genetic engineering is an abomination. Is it not time that molecular biologists (and their representatives and friends in organizations like the Deutsche Forschungsgemeinschaft) stirred themselves for long enough to demonstrate that there is another tale to tell? Temporarily, at least, they may have to resort to sloganeering: how about, for starters, "Is there a cure for AIDS without genetic engineering?".

West German researchers, self-effacing lest they seem otherwise, will not find this easy. Worse, they will have to win over politicians and electors at best unfamiliar with what genetic engineering is, but who have been persuaded by the past decade and a half of radical (and anti-intellectual) environmentalism that democratic prizes go to those who shout the loudest. The particular issue of genetic engineering, semantically linked as it is in West Germany with still recent horrors at places such as Auschwitz, is bound to be difficult. But that is merely another reason why the academic community should stir itself in its own interests. 